\title{
Tuberculomas cerebrales: reporte de caso
}

\author{
Bety Gómez Arias ${ }^{1}$, Luis Alfonso Zarco Montero ${ }^{2}$
}

\section{Resumen}

El compromiso del sistema nervioso central por tuberculosis, continúa siendo una causa importante de morbi-mortalidad en los países en vías de desarrollo.

Presentamos el caso de una paciente con meningitis y tuberculomas en el sistema nervioso central y discutimos los métodos diagnósticos disponibles en la actualidad para esta patología.

Palabras clave: tuberculosis, tuberculomas, meningitis.

\section{Title}

Cerebral tuberculoma: a case report

\begin{abstract}
The central nervous system (CNS) involvement due to tuberculosis has been an important cause of morbid-mortality in third world countries.

We present a clinical case of a patient with meningitis and CNS tuberculomas, and discuss the diagnostic tests available for this pathology actually.
\end{abstract}

Key words: tuberculosis, tuberculomas, meningitis.

1 Residente de IV año de Neurología, Pontificia Universidad Javeriana.

2 Neurólogo clínico, profesor asistente, Pontificia Universidad Javeriana. 


\section{Introducción}

A pesar de la existencia de programas de control de infecciones en todo el mundo y antibióticos a los cuales la micobacteria es sensible. La tuberculosis del sistema nervioso central permanece siendo una causa de enfermedad y muerte en países en vía de desarrollo. Es así como el 5 al $15 \%$ de los individuos expuestos a la tuberculosis desarrollan enfermedad sintomática y del 5 al $10 \%$ de éstos, tienen compromiso del sistema nervioso central[1].

Se presenta el caso de una mujer de 44 años de edad, residente en Bogotá, que consultó al servicio de Neurología del Hospital Universitario de San Ignacio por dos meses y medio de evolución de cefalea global, tipo pulsátil de intensidad progresiva hasta 7/10, asociada a náusea, vómito, fotofobia, dificultad progresiva para la articulación del lenguaje, astenia, adinamia y pérdida de peso de $10 \mathrm{ki}-$ logramos en los últimos dos meses.

Como antecedente de importancia presentó diabetes gestacional en el último embarazo, el cual había terminado 2 meses y medio atrás. Requirió cesárea por insuficiencia placentaria y como complicaciones desarrolló infección y dehiscencia de la herida quirúrgica.

$\mathrm{Al}$ examen físico de ingreso se evidenció: presión arterial 120/70 mm
$\mathrm{Hg}$, frecuencia cardiaca de 84 por minuto, frecuencia respiratoria de 18 por minuto, temperatura de $36.5^{\circ} \mathrm{C}$, ruidos cardiacos rítmicos, ruidos respiratorios sin agregados, abdomen con cicatriz quirúrgica sana.

$\mathrm{Al}$ examen neurológico estaba alerta, desorientada en tiempo y espacio, hipoprosexica, bradipsíquica, disártrica, con compromiso de memoria de trabajo, episódica, cálculo, apraxia ideomotora y agnosia digital. En el fondo de ojo no se observó papiledema. Había dismetría bilateral de predominio izquierdo y latero pulsión hacia la izquierda.

Se realizó un diagnóstico por síndromes: frontal de la convexidad, parietal angular izquierdo y cerebeloso hemisférico bilateral, de topografía multifocal, y teniendo en cuenta la insuficiencia placentaria y la pérdida significativa de peso se consideró como primera opción etiológica un proceso infeccioso crónico por tuberculosis (TBC) u hongos.

En los exámenes para clínicos de ingreso se encontró: hemoglobina $14.5 \mathrm{mg} / \mathrm{dl}$, hematocrito $45.6 \mathrm{mg} / \mathrm{dl}$, glóbulos blancos 9.700 neutrófilos $83,4 \%$, linfocitos $9,4 \%$ plaquetas 423.000/ul, velocidad de eritrosedimentación en $11 \mathrm{~mm} / \mathrm{h}$ y Elisa para VIH negativo.

En la tomografía computarizada de cráneo simple y con contraste se ob- 
servaron 17 lesiones anulares, de 3 a $12 \mathrm{~mm}$ de diámetro, ubicadas en la sustancia blanca de ambos hemisferios cerebrales, con realce periférico y edema vasogénico asociado; Además, se encontraron lesiones en el pedúnculo cerebral izquierdo y la región del tegmento. Como posibilidades diagnósticas de estas lesiones se planteó: tuberculosis u hongos (Cryptococcus sp., Aspergilus sp. e Histoplasma sp.).

En la radiografía de tórax se observó un infiltrado micronodular diseminado en ambos campos pulmonares, sugestivo de tuberculosis miliar.

En la resonancia magnética cerebral simple y contrastada se encontró compromiso multifocal del parénquima cerebral por lesiones anulares de predominio en la unión corticosubcortical, con realce a la administración del medio de contraste y edema vasogénico alrededor de las lesiones.

Se practicó un primer estudio de líquido cefalorraquídeo con presión de apertura de $22 \mathrm{~cm}$ de agua, aspecto límpido, incoloro, con 26 leucocitos, $60 \%$ linfocitos y $40 \%$ neutrófilos, proteínas $175 \mathrm{mg} / \mathrm{dl}$, glucosa $28 \mathrm{mg} / \mathrm{dl}$ con glucemia central $83 \mathrm{mg} / \mathrm{dl}$; los estudios de tinta china, látex para Cryptococcus sp., inmunodifusión para Aspergillus sp., Coccidioides sp. e Histoplasma sp., y la coloración para bacilos ácido-alcohol resistentes (BAAR), fueron negativos. Se practicó un nuevo estudio de líquido cefalorraquídeo 5 días después, que mostró un examen citoquímico de similares características. No se pudo realizar reacción en cadena de la polimerasa (PCR) para tuberculosis. Los cultivos para Micobacteria spp. Fueron negativos a las 12 semanas en 2 muestras diferentes.

Debido a las características del estudio citoquímico de líquido cefalorraquídeo, las imágenes de tomografía, las de resonancia magnética cerebral, y la radiografía de tórax, se hizo un diagnóstico de meningoencefalitis tuberculosa con clasificación grado II según los criterios clínicos del Modified British Medical Research Council[2], (véase tabla 1) y se inició tratamiento tetra conjugado con isoniacida, rifampicina, pirazinamida y estreptomicina, y además dexametasona a dosis de $0.4 \mathrm{mg} / \mathrm{kg}$ diarios intravenosos con descenso gradual.

Posteriormente se confirmó el diagnóstico de tuberculosis miliar, mediante biopsia de pulmón a cielo abierto que mostró una infección granulomatosa crónica, con coloraciones positivas para micobacteria.

La paciente fue dada de alta con tratamiento médico, pero dos meses después reingreso por presentar dos crisis epilépticas descritas con postura tónica y movimientos clónicos generalizados, en el examen neurológico se evidenció el papiledema. 
Se realizó una nueva resonancia magnética cerebral que mostró múltiples lesiones focales intraaxiales supra e infratentoriales atribuidas a tuberculomas, edema cerebral de ambos hemisferios y mastoiditis izquierda. Se inició tratamiento anticonvulsivante con carbamazepina y esteroides endovenosos; Posteriormente, se practicó biopsia cerebral que mostró gliosis reactiva, focos de hipomielinización, y congestión, las coloraciones de Ziehl Neelsen y PAS fueron negativas para microorganismos.

Se decidió continuar tratamiento antituberculoso hasta completar nueve meses.

El control clínico posterior al tratamiento evidenció en el examen neurológico fallas de atención y memoria de trabajo únicamente, y el estudio de resonancia cerebral y con contraste mostró mejoría significativa.

\section{Discusión}

Los métodos diagnósticos para la detección de micobacteria tuberculosa en líquido cefalorraquídeo van desde la tinción de BAAR en sedimento con una sensibilidad del 5 al 25\%[3], la reacción en cadena de la polimerasa (PCR), con una sensibilidad que varía del 33 al $90 \%$ y especificidad del 88 al $100 \%$ [4].

El cultivo de líquido cefalorraquídeo sigue siendo el patrón diagnóstico de oro, a pesar de las desventajas: 1.
Requiere grandes volúmenes de líquido cefalorraquídeo para optimizar la sensibilidad del aislamiento 2. $20 \%$ de los pacientes con diagnóstico clínico tienen cultivos negativos[1]. 3. El crecimiento bacteriano demora entre 6 a 8 semanas, por lo cual no es un método de diagnóstico temprano[2].

La medición de adenosin deaminasa (ADA) en líquido cefalorraquídeo es actualmente una herramienta útil para el diagnóstico diferencial temprano, con un punto de corte de $11.39 \mathrm{u} /$ L/min, pudiéndose realizar en cualquier laboratorio de patología donde no estén disponibles métodos más sofisticados[4]. La sensibilidad de este método alcanzó el $83 \%$ y la especificidad el $86 \%$ según un estudio donde se comparó con un método ELISA que media el complejo antígeno 85 previamente identificado en pacientes con tuberculosis meníngea, lo que reafirma su utilidad[5].

En el caso de esta paciente, es importante anotar que no se pudo aislar la micobacteria en el líquido cefalorraquídeo ni por biopsia cerebral, pero sí se confirmó la existencia de una enfermedad granulomatosa crónica (tuberculosis extraneural) con biopsia de pulmón y esto, en un paciente con un cuadro clínico sugestivo se considera confirmatorio del diagnóstico[1].

Otro hallazgo importante fue la presencia concomitante de meningitis tuberculosa y tuberculomas lo cual se 
evidencia en menos del $10 \%$ de los pacientes en la mayoría de grandes series clínicas. Ocasionalmente los tuberculomas se desarrollan durante un curso previo al manejo antituberculoso o después de éste[1], pero, en un estudio publicado en 2007 por Thwaites y cols.[6] sobre el efecto de la dexametasona en la patología cerebral de la tuberculosis meníngea, el $74 \%$ de los pacientes tenía tuberculomas en la resonancia magnética realizada 60 días después del inicio del tratamiento. Se concluyó que son parte de la respuesta normal al tratamiento de la infección.

El tuberculoma resulta cuando pequeños tubérculos en el cerebro no se rompen en el espacio subaracnoideo pero continúan creciendo, desde la pared del parénquima cerebral y las meninges en una densa cápsula fibrosa; en el microscopio se ve como un centro necrótico caseoso, rodeado por células epitelioides, gigantes de Langhans y linfocitos[1].

Las secuelas clínicas son las de una o múltiples lesiones cerebrales que, en grandes series no sobrepasan las doce lesiones. En este caso se encontraron 17 lesiones iniciales. Generalmente se visualizan en los hemisferios cerebrales, ganglios basales, cerebelo y tallo cerebral y se correlacionan con los síntomas que presentan los pacientes. En el presente caso, las crisis convulsivas, el aumento de la presión intracraneana y el déficit neurológico focal (síndrome parietal angular y cerebeloso izquierdo) reflejaron la localización de las lesiones.

La falta de evidencia de estudios controlados para el manejo de la tuberculosis meníngea, hace que muchas de las recomendaciones combinen los principios del tratamiento de la tuberculosis pulmonar con los datos farmacocinéticos que predicen las concentraciones intracerebrales de las drogas antituberculosas. Los primeros dos meses de tratamiento -"fase intensiva" deben ser con isoniacida, rifampicina, pirazinamida, $y$ etambutol estreptomicina o etionamida, y la "fase de mantenimiento" hasta completar entre 9 a 12 meses deben ser con isoniazida y rifampicina; aunque resúmenes sistemáticos concluyeron que 6 meses podrían ser suficientes, si la posibilidad de resistencia a los medicamentos era baja[2].

El retraso en el diagnóstico y tratamiento de la meningitis tuberculosa, son los mayores factores que contribuyen a la alta mortalidad reportada en estudios recientes[6], es por esto que el inicio del tratamiento tetra conjugado debe hacerse con la sospecha diagnóstica. La adición de corticoesteroides había sido controversial, pero actualmente se considera que en pacientes VIH negativos con tuberculosis meníngea son útiles al reducir el déficit neurológico residual discapacitante y la mortalidad entre los sobrevivientes[7], no es así de claro para los pacientes con infección por VIH y TBC. 


\section{Imágenes diagnósticas}
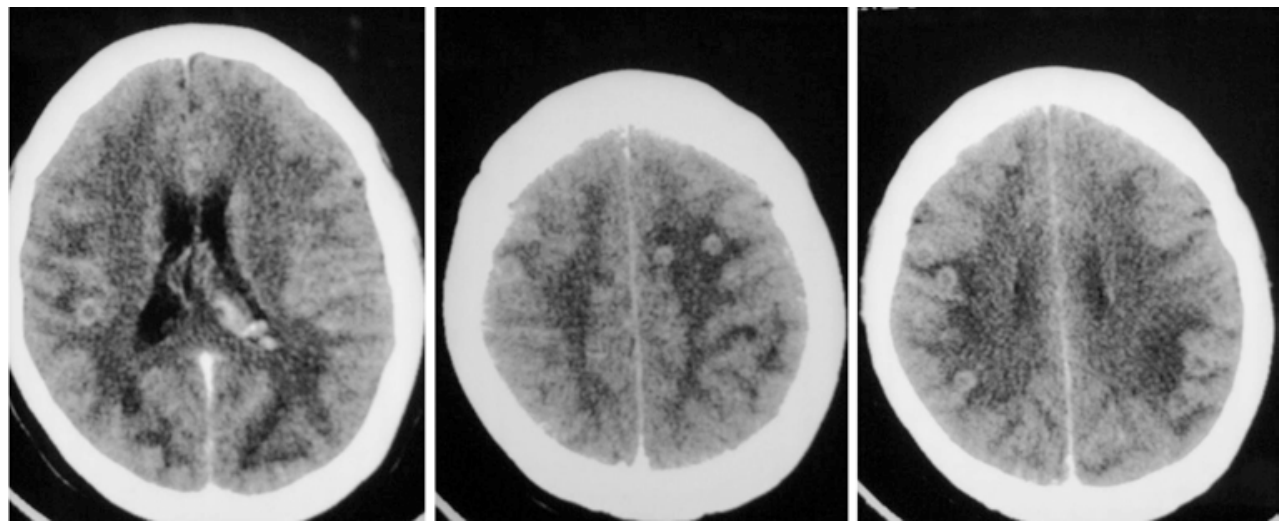

Figura 1. Tomografía de cráneo con contraste.
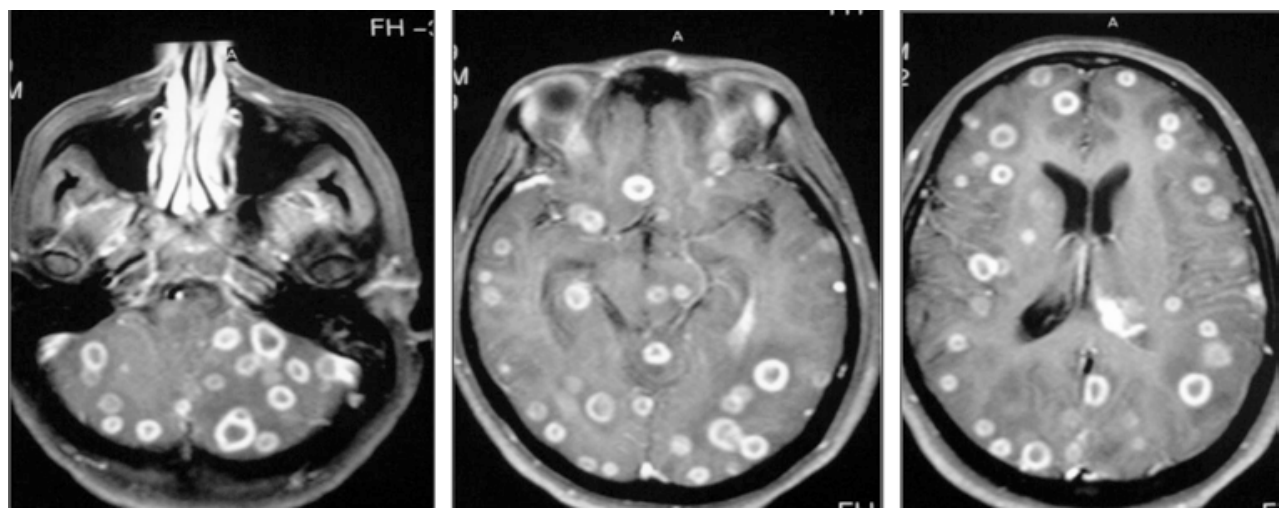

Figura 2. Primer estudio de resonancia magnética cerebral simple y con contraste.
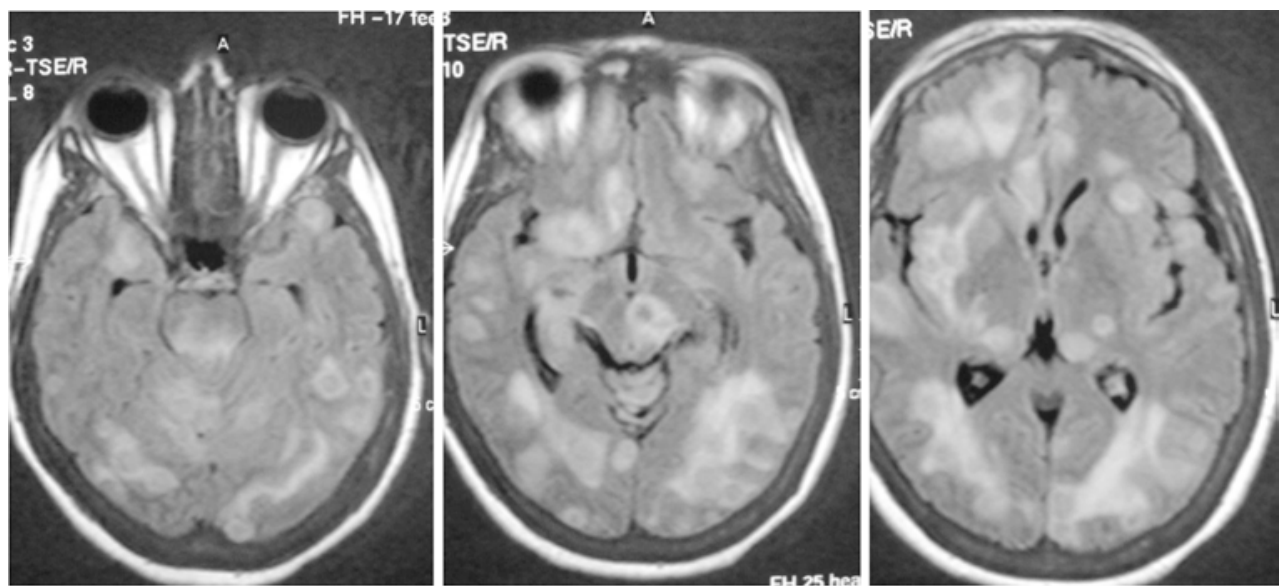

Figura 3. Resonancia magnética cerebral a los dos meses de tratamiento. 


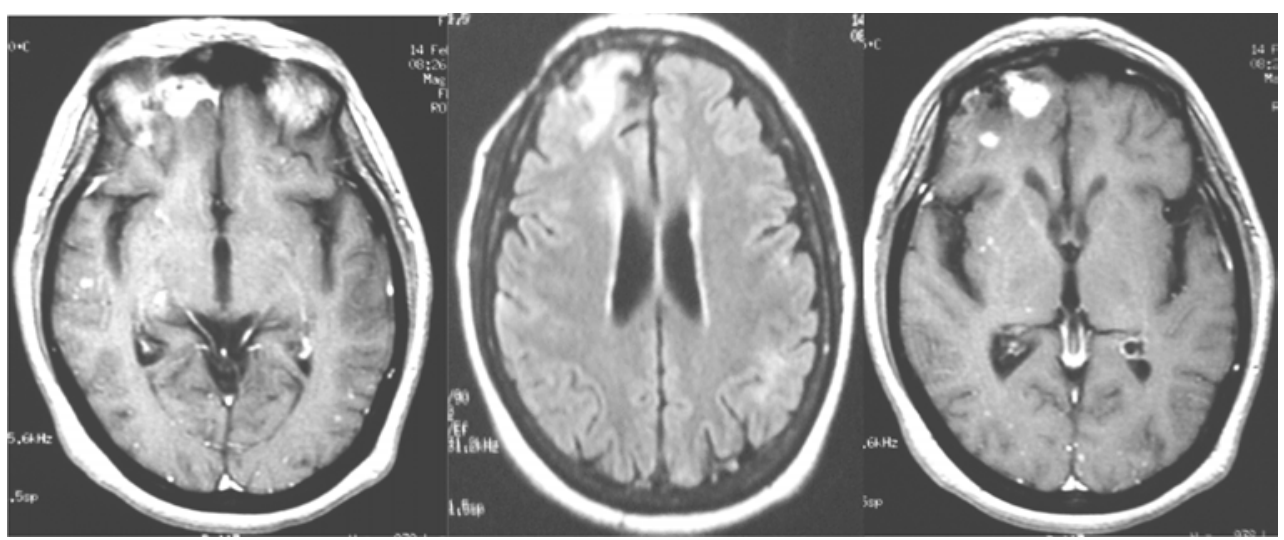

Figura 4. Resonancia magnética cerebral postratamiento.

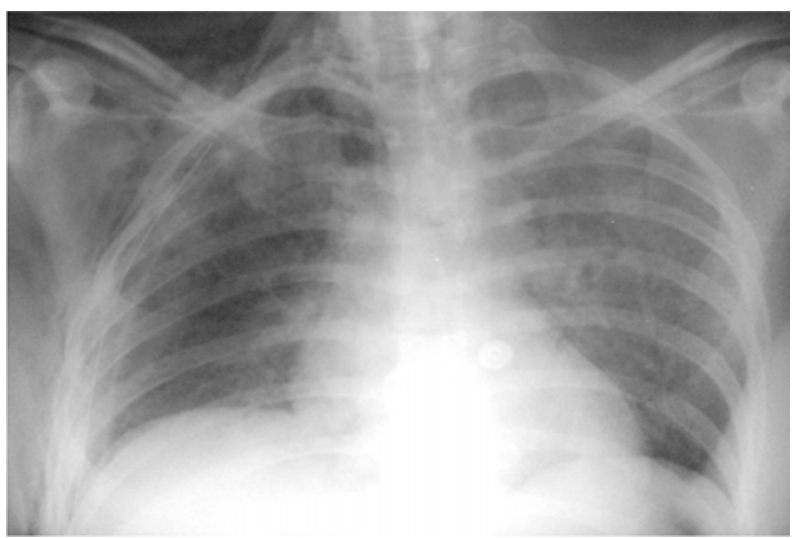

Figura 5. Rayos $X$ de tórax al ingreso.

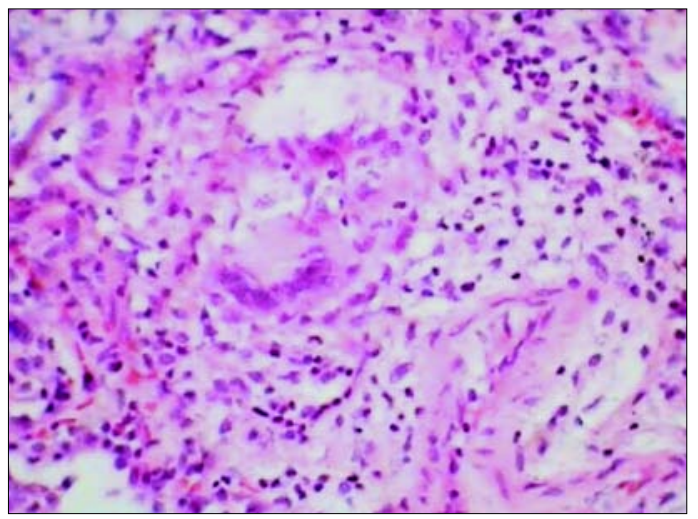

Figura 6. Biopsia de pulmón derecho. 
Tabla 1. (Bibliografía 2)

\section{The Modified British Medical Research Council}

Criterios clínicos para los grados de severidad de la tuberculosis meníngea

\section{Grado I}

Alerta y orientado sin déficit neurológico focal

\section{Grado II}

Escala de coma Glasgow entre 14-10, con o sin déficit neurológico focal, o escala de coma Glasgow de 15 con déficit neurológico focal.

\section{Grado III}

Escala de coma Glasgow menor de 10 con o sin déficit neurológico focal.

\section{Bibliografía}

1. Abigail Zuger. Tuberculosis. Infections of the central nervous system, 3rd edition, Lippincott Williams and Wilkins, 2005; capítulo (25):441-59.

2. Guy E. Thwaites. Tuberculos meningitis: many questions, too few answers. Lancet Neurology, marzo 2005;(4): 160-70.

3. Larry E. Davis. Subacute and chronic meningitis. Continuum: Lifelong Learning in Neurology. 2006;12,27-57.

4. Rajpal S. Kashyap, Rani P Kainthla, Anju V Mudaliar, Hemant J Purohit, Girdhar M Taori, and Hatim F Daginawala. Cerebrospinal fluid adenosine deaminase activity: a complimentary tool in the early diagnosis of tuberculous meningitis. Cerebrospinal Fluid Research, marzo 2006;3:5.
5. Rajpal S Kashyap, Sonali P Ramteke, Poonam S Deshpande, Hemant J Purohit, Girdhar M Taori, and Hatim F Daginawala. Comparasion of an adenosine deaminase assay with ELISA for the diagnosis of tuberculous meningitis infection. Med Sci Monit, 2007;13(9): BR200-04.

6. Guy E Thawaites, Jeremy MacmullenPrice, Tran Thi Hong Chau, Pham Phuong Mai, Nguyen Thi Dung, Cameron P Simmons, Nicholas J White, Tran Tinh Hien, David Summers, Jeremy J Farrar. Serial MRI to determine the effect of dexamethasone on the cerebral pathology of tuberculous meningitis: an observational study. Lancet Neurol 2007;6:230-6.

7. Prasad K. Singh MB. Corticosteroids for managing tuberculous meningitis (Review). Cochrane database of systematic review, 2008; Issue 1. 